\title{
LA LITERATURA EN LA FORMACIÓN DE JUECES Y ABOGADOS
}

\author{
TERESA ARSUAGA ACASO \\ Ilustre Colegio de Abogados de Madrid \\ ayamedia.solu@gmail.com
}

\section{RESUMEN}

El papel que la literatura puede desempeñar en la formación de los jueces y los abogados es una cuestión que se plantea en este artículo a través de la presentación de algunas de las aportaciones más significativas que desarrollaron en este campo James Boyd White y Richard Weisberg. Ambos son autores principales del influyente movimiento Law and Literature Studies, nacido a comienzos de los años setenta del pasado siglo en las universidades norteamericanas.

La literatura se convierte sus manos en un instrumento privilegiado para abordar, desde una perspectiva distinta a la habitual, temas fundamentales del Derecho, en especial, aquellos que conciernen al ejercicio de la profesión de abogado y a su función cívica de progreso social. Con esta formación literaria se pretende mejorar las competencias de los abogados y jueces como lectores, críticos y compositores de textos, de forma que puedan desarrollar estas tareas propias de su trabajo con éxito y eficacia, con conciencia de su actividad genuinamente literaria y con mayor compromiso con el progreso social en términos de justicia.

PALABRAS CLAVE: derecho, literatura, crítica literaria, texto, lenguaje, comunicación.

\section{LITERATURE IN THE TRAINING OF JUDGES AND LAWYERS}

\section{ABSTRACT}

The role of literature in the training of judges and lawyers is an issue raised in this article through the presentation of some of the most significant contributions that James Boyd White and Richard Weisberg made in this field. Both are leading representatives of the influential Law and Literature Studies movement, born in the early seventies at American universities. Literature becomes, in the hands of these authors, a privileged instrument to address, from a new perspective, essential issues of law, especially those concerning the practice of law and the lawyer's role in social progress.

Literary training would be aimed at improving the skills of lawyers and judges as readers, critics and composers of texts, so that they could carry out these characteristic tasks of their work successfully and effectively, with greater awareness of their genuinely literary activity and a stronger commitment to the progress of society towards justice through the tools of law.

KEYWORDS: law, literature, literary criticism, text, language, communication.

\section{INTRODUCCIÓN}

El papel que la literatura puede desempeñar en la enseñanza del Derecho es una cuestión que podría abordarse desde perspectivas diversas. En este artículo se hará una presentación de algunas de las más interesantes aportaciones que, sobre esta materia, han realizado dos de los principales representantes del movimiento 
norteamericano denominado «Law and Literature Studies»: James Boyd White y Richard Weisberg (Arsuaga 2015). ${ }^{1}$ Este movimiento nació a comienzos de los años setenta del pasado siglo en el seno de las universidades norteamericanas y, desde entonces, no ha dejado de crecer en importancia gracias a las numerosas aportaciones doctrinales - que han dado lugar a intensos debates académicosy a su progresiva implantación en los planes de estudios de las escuelas de Derecho (Gemmette 1989 y 1995). ${ }^{2}$

No se trata, por tanto, de presentar un campo nuevo, aunque sí de mostrar algunas de las posibilidades que plantea esta relación interdisciplinar en la formación de los juristas $\mathrm{y}$, ello, desde unos presupuestos aún hoy poco conocidos en España. ${ }^{3}$

Este movimiento agrupa una gran cantidad de propuestas muy heterogéneas. ${ }^{4}$ No existe, pues, uniformidad de planteamientos, ni unos principios programáticos asumidos por todos sus miembros. Sin embargo, aun siendo esta su naturaleza, sí podría decirse que esta corriente del Derecho - que va mucho más allá de una mera asociación de dos disciplinas - tiene en su origen el objetivo compartido de contrarrestar los riesgos e insuficiencias del modelo positivista en la concepción práctica y en la enseñanza del Derecho.

En efecto, los distintos autores compartirían la idea de que una visión conceptualizada y abstracta del Derecho y de neutralidad de su lenguaje, resulta insuficiente y no se adecúa, verdaderamente, a la naturaleza del Derecho. En este sentido, podría decirse, que muchas de las propuestas en el seno de este movimiento buscarían ir más allá de la concepción de esta disciplina como una

${ }^{1}$ La cita se refiere a una tesis doctoral en la que se desarrollan con amplitud y profundidad las aportaciones de White y Weisberg en este campo, algunas de las cuales, se presentan en este artículo. Asimismo puede encontrarse en ella una extensa bibliografía con los principales autores del movimiento y sus contribuciones doctrinales más significativas.

2 En lawlit.blogspot.com/ es posible acceder a una exhaustiva relación de los libros y artículos sobre Derecho y Literatura publicados desde 1982 hasta el 2006, así como a una muestra amplia de textos literarios sobre Derecho. En esta misma dirección se recoge, también, un Syllabus sobre la materia dirigido por el profesor Slove en la George Washington University Law shool en el 2010. Elizabett Gemette en dos artículos lleva a cabo un estudio sobre los cursos de Derecho y Literatura en las escuelas de Derecho norteamericanas a finales de los años ochenta, así como de la expansión que estos llegaron a alcanzar en los años noventa.

${ }^{3}$ En España es aún escasa su recepción en el ámbito académico y doctrinal. Es, además, en la actualidad, muy insignificante el número de universidades que incorporan esta propuesta interdisciplinar. Entre los autores que en España muestran conocimiento y cierta recepción del movimiento, podrían destacarse Calvo (2006), Talavera (2006), Carreras (1996), Falcón (2015). Especial interés, aunque fuera del territorio español, puede tener el más reciente trabajo de Marrano-Fente (2016), ya que constituye una aplicación de las tesis de White al ámbito del lenguaje jurídico español, en concreto, al estudio de las leyes de Burgos (1512).

${ }^{4}$ Dentro del movimiento Derecho y literatura hay propuestas de naturaleza muy diversa. En concreto, los planteamientos de los autores que se presentan en este artículo, White y Weisberg son, en buena medida, una reacción frente a las posturas más postmodernas dentro del movimiento, especialmente a la que mantiene Fish. 
estructura autosuficiente de normas, instituciones y reglas de funcionamiento que permanece cerrada e impermeable a otros lenguajes. Estarían cuestionando, también, por tanto, la idea de que del jurista se espera, únicamente, una respuesta impersonal, carente de todo juicio de valor, y la utilización de un tipo de razonamiento cuyo objetivo sea alcanzar una solución predeterminada a través de la aplicación de la lógica a partir de la norma.

Podría decirse, a su vez, que son estudios que tienen su origen en la observación del enorme protagonismo que había adquirido el discurso científico en el Derecho. La multitud de argumentos, sentencias y artículos académicos cargados de jerga científica, datos y estadísticas, serían reflejo del exceso de confianza que el Derecho había depositado en las ciencias sociales de tipo positivista. Especial relevancia, en este sentido, tiene la extraordinaria influencia que comenzó a adquirir, a principio de los años setenta del pasado siglo, el movimiento Law and Economics, algo que resulta impulsado o favorecido por la posición de dominio que, progresivamente, ha llegado a ocupar la concepción económica de nuestra vida en común. Estos autores no niegan que estas ciencias ofrezcan métodos de análisis de valor para el Derecho, pero advierten de la necesidad de que las limitaciones de su lenguaje sean comprendidas y sujetas a la disciplina del Derecho.

\subsection{El lenguaje científico y conceptual versus el lenguaje literario}

Una parte importante de las propuestas en el seno del movimiento Derecho y literatura surgen, pues, para poner en evidencia y corregir los riegos derivados de la adopción acrítica por el Derecho del lenguaje científico (Nussbaum 1995). ${ }^{5}$ El motivo es la consideración de que los efectos de este fenómeno pueden resultar contradictorios y nocivos para el funcionamiento no solo del Derecho y su objetivo de hacer justicia, sino, también, para el desarrollo saludable de una democracia. Por un lado, son métodos que manejan una imagen muy reducida del ser humano, que se limita a lo material y medible, cuya generalización no resulta adecuada para una disciplina como el Derecho que regula la conducta de seres humanos, cuyos comportamientos son complejos y difícilmente reducibles a estas categorías. Además, no sería una idea coherente dentro de un sistema democrático, el cual presupone una concepción mucho más amplia de los ciudadanos al depositar y exigir de ellos una gran responsabilidad. Por otro lado, una consecuencia de la forma en que se están aplicando estos métodos en el Derecho, es el riesgo de olvidarse del modo de proceder característico de este último, esencial para la democracia, a través de los textos, acuerdos, principios y convenciones del pasado que lo configuran. Para estos autores se está prescindiendo del Derecho mismo en favor de otros lenguajes cuyos propósitos

\footnotetext{
${ }^{5}$ Junto a White y Weisberg, Martha Nusbaum es una de las autoras dentro del movimiento que pone más énfasis en este aspecto.
}

ANU.FILOL.ESTUD.LINGÜÍST., 7/2017, pp. 125-148., ISSN: 2014-1408. DOI: 10.1344/AFEL2017.7.7 
pueden ser distintos del de hacer justicia. Depositar un exceso de confianza en ellos conduce, entonces, a una reducción de la imagen del mundo a las categorías rígidas que este tipo de lenguajes requieren.

Las ciencias sociales de tipo positivista requieren para operar que el lector y el escritor conciban su lenguaje como neutral, como uno que describe sin distorsión lo que está fuera en el mundo y, al igual que en el discurso conceptual, presupone que sus palabras son entidades diferenciadas, definibles y, por tanto, sus significados objetivos. Es White (1990: 23-86) uno de los autores que más ha cuestionado la generalización de esta clase de lenguaje en el ámbito público, académico y, especialmente, en el Derecho.

$Y$ es que el autor, que pertenece al giro lingüístico, se acerca, contrariamente, a las posiciones de Wittgenstein relativas al lenguaje ordinario. Estas suponen una forma de pensar en el lenguaje que es la que nace de nuestra experiencia de la vida ordinaria y de la literatura. Desde esta perspectiva, las palabras mismas no tendrían un significado propio y neutral que permanece inalterable a los diferentes usos que pueda hacerse de ellas, sino que este sería siempre dependiente de las frases y expresiones en las que las palabras se encuentren, así como del contexto lingüístico, intelectual, social y cultural al que pertenezcan. Según esta forma de entender el lenguaje, las palabras no tendrían, ni siquiera, un mismo significado para todas las personas que las usan. White señala, en este sentido, que aunque cada uno de nosotros aprendemos nuestros lenguajes, en gran medida, por imitación, actuando por un sentido de lo que es apropiado a cada situación, siempre hay una dimensión del significado que es irremediablemente personal, que deriva de una experiencia del lenguaje y de la vida que difiere en cada uno de nosotros.

El lenguaje no sería, entonces, un mero instrumento de elaboración conceptual o de simple intercambio de información, sino algo mucho más rico y complejo (White 1987: 1962). Se trataría de un material vivo con el que construir el significado de nuestras vidas individuales y colectivas y donde, además, se encuentran implícitos los términos de descripción, los motivos y los valores que hacen de cada cultura lo que es. Cada uno de los seres humanos, a su vez, estaría formado por los lenguajes que hereda y utiliza, ya que a través de los mismos se va conformando en ellos su forma de ver el mundo y sus sentimientos hacia él. El lenguaje denota una concepción del mundo y forma quiénes somos, determinando nuestra manera de observar y construir el mundo. Y todo ello en un proceso activo y no estático, en la medida en que estamos continuamente rehaciendo el lenguaje a través del uso particular que hacemos del mismo. Cada vez que hablamos o escribimos, en grados diferentes y de una forma más o menos expresa, contribuimos siempre a crear nuevos significados. Desde este punto de vista, lo que haría diferente, realmente, a unas culturas de otras y a los individuos como sujetos con culturas, son nuestros lenguajes y nuestras diferentes maneras de dar significado a la experiencia. 
White admite, pues, que en determinados momentos el discurso conceptual y científico es útil y necesario, pero considera que no debería ser concebido como el modelo de todo lenguaje, sino, más bien, como un tipo especial del mismo cuya utilización ha de ser siempre explicada y justificada. Su propuesta en el campo del Derecho y la literatura podría decirse que, en gran medida, tiene la pretensión de demostrar cómo esta forma de entender el lenguaje del Derecho es más acorde con la verdadera naturaleza de esta disciplina, e indaga e investiga sobre las posibilidades que esta concepción más literaria del lenguaje podría reportar al Derecho y a los juristas en su función de hacer justicia.

$Y$ es que el anhelo de certeza característico de los métodos científicos, cuando se aplica a cuestiones como la justicia, la ética y sobre nuestras vidas sociales y prácticas resulta, para White (1990: 40), falso y poco adecuado, al no estar en concordancia con la naturaleza de este mundo y con nuestra experiencia a través del lenguaje. En su opinión, una actuación racional, cuando se tratan materias como estas, sería la de asumir la radical incertidumbre de la existencia humana, los límites del lenguaje y de nuestras propias mentes, así como la naturaleza y contingencia de las convicciones con las que funcionamos. Un lenguaje adecuado para la razón y para la justicia sería el que acepta las condiciones literarias en las que vivimos y asume, por tanto, que todo lo que decimos, todo lo que somos, se debe en parte al contexto en el que vivimos, siempre imperfectamente percibido y en permanente cambio.

No es a la búsqueda de certezas, entonces, a lo que deba aspirarse, ya que sería un objetivo inalcanzable en estas circunstancias, sino a aprender a vivir en la incertidumbre. Por ello White (1986: 1375), frente a la tendencia que percibe por aislar el Derecho de todo contexto para su estudio científico, orientando todo el esfuerzo a establecer clasificaciones o categorías que sirvan para describir y predecir el fenómeno jurídico de una forma científica y neutral en cuanto a valores, propone verlo como una actividad más del lenguaje a través de la cual la sociedad y la cultura se hacen a sí mismas, constituidor de ellas pero, a la vez, constituido por ellas.

\subsection{Una nueva forma de ver el derecho, su práctica y enseñanza}

Con esta imagen más literaria del Derecho, que busca contrarrestar la más extendida concepción del mismo como una disciplina abstracta, mecánica, impersonal y burocrática, White y Weisberg estarían resistiéndose, fundamentalmente, a un ejercicio y una enseñanza del Derecho que, en su opinión, empequeñece más que amplía la capacidad humana, en general, y de los prácticos del Derecho, en particular, para la experiencia, la comprensión, la imaginación y la empatía.

El modo en que estos autores buscan corregir el rumbo del Derecho en dirección a lo literario, no es teorizando o formando parte en los múltiples 
debates académicos sino, sobre todo, a través de la elaboración de una nueva propuesta de formación para futuros abogados y jueces a través de la literatura.

Bajo estas propuestas subyace una concepción del Derecho y su práctica que, en opinión de ambos, se adecúa más, como se ha señalado en el epígrafe anterior, a la verdadera realidad y experiencia de los seres humanos, a las auténticas circunstancias de nuestra existencia (siempre imperfectamente percibidas y en constante cambio), a la naturaleza del Derecho y su forma característica de funcionar.

Dentro de esta concepción podrían destacarse dos cuestiones de especial trascendencia:

a) Se pone en cuestión la pretensión, característica de los métodos científicos y positivistas, de que la actuación de los jueces y los abogados sea neutral e impersonal. Se critica el exceso de confianza que estos depositan en los datos de carácter fáctico, tan bien recibidos en un ambiente, dentro del Derecho, en el que todo juicio de valor ha de ser eliminado o reglamentado al ser visto con recelo o temor.

Estos autores hacen un análisis de la actividad de los profesionales del Derecho en el que se destaca lo inevitable, siempre, de una respuesta personal ante cada caso que se les plantea. Estas respuestas, que contienen un juicio o apreciación subjetiva del juez o del abogado, no pueden ni deben ser erradicadas del Derecho, sino que, más bien, tendrán que educarse y disciplinarse para garantizar que sean adecuadas y responsables. Esta realidad no solo debe aceptarse en el Derecho, sino que, además, debe entenderse que esas intuiciones, juicios y decisiones conscientes o inconscientes de los prácticos del Derecho, si son adecuadamente disciplinadas, pueden constituir la oportunidad para que el Derecho se haga vivo, para su consolidación, transformación o desarrollo.

b) La razón es que, para estos autores, el Derecho no es una disciplina aislada y autónoma, sino integrada en el devenir de la cultura. Esto exige de sus prácticos, además del conocimiento de las normas jurídicas y la doctrina, otro tipo de habilidades que les permitan adaptar el Derecho de forma adecuada, responsable y eficaz a las nuevas y diferentes realidades en permanente mutación. «Students seek out good teaching to learn not the rules but the culture, for the rules are everywhere the same» (White 1982: 437)

Es precisamente esto último, lo que ambos autores pretenden con la formación literaria que elaboran para los juristas. Ante la pregunta de qué método utilizar, los dos están de acuerdo en que no es posible a través de unas reglas predeterminadas, ni tratando de erradicar todo juicio personal, sino solo con un tipo de educación para la cual la literatura es un instrumento esencial. 


\subsection{Por qué la literatura}

Porque, según estos autores, la única guía posible para orientar a los jueces y abogados en esos juicios individuales (ineludibles en su trabajo) es una interna, para la que no es suficiente el conocimiento de las normas y de la doctrina. Sería necesario, además, una formación más integral que proporcionase a estos profesionales madurez intelectual, capacidad crítica cultural, el dominio de ciertas habilidades literarias, así como una cierta calidad en el pensamiento y la expresión. Esta educación extrajurídica es la que les capacitaría para afrontar, adecuadamente, las dificultades que les plantean las complejas actividades con el lenguaje que configuran sus tareas diarias.

Este tipo de aprendizaje - que en la visión de estos autores es más artístico que técnico - no es posible a través de la teoría o a través de reglas, ya que ambas requieren de una respuesta impersonal del que las recibe, la asunción por parte de este de unos presupuestos y el deseo de cumplir unas expectativas. Teoría y reglas no fomentan la repuesta individual que precisa un juicio que, además, ha de ejercitarse en situaciones muchas veces difícilmente previsibles. La literatura, en cambio, proporciona una forma de educar que permite experimentar, hacer propio lo aprendido y, a partir de la interiorización y del aprendizaje individual, poder actuar en las situaciones más diversas.

Estos autores ven en determinadas obras de la literatura una vía idónea de formar a los prácticos del Derecho en estos aspectos permanentes de su trabajo, los cuales, presentan similitudes con las actividades del escritor y del crítico literario, pudiendo ser útil, entonces, el adquirir cierto conocimiento y algunas de las habilidades siempre asociadas con aquellos. Abogados, jueces y escritores se ven inmersos, como se ha visto, en una actividad retórica, de la mente y el lenguaje, a través de la cual construyen significados en condiciones de incertidumbre. Partiendo de esta identidad, es posible que los primeros puedan aprender algo de los logros intelectuales que, en este sentido, han quedado preservados en los grandes textos literarios del pasado.

Para poder aprender de ellos, para que puedan ser textos de nuestro presente también, habría que partir, entonces, del presupuesto previo de considerar a sus autores como hombres y mujeres que, desde unas circunstancias similares a las nuestras - en parte formados por los lenguajes, las culturas, por las prácticas de la vida social e intelectual que configuraban el mundo que conocieron - rehicieron o reconstituyeron, a través de sus composiciones, los lenguajes y las prácticas que heredaron y que conformaban su mundo. Serían, por tanto, sus luchas con los lenguajes, las que podrían hablarnos, en la medida que también nosotros luchamos con los nuestros.

La lectura de determinadas obras de la literatura se plantea, entonces, como una forma de conexión con el pensamiento humano trabajando de la manera más profunda y mejor sobre las cuestiones más importantes de nuestras vidas individuales y colectivas. En los textos que White admira, como los de Virgilio, 
Shakespeare, Jane Austen o Robert Frost, lo que el autor encuentra es personas hablando, lo mejor que pueden, sobre aquello que era más importante para ellas, haciendo frente, constantemente, a sus propios límites de perspectiva y de conocimiento. Leer estos textos, de esta manera, fue para el autor una escuela sobre pensar, leer y escribir bien, y siempre sobre las cuestiones que más importan de la vida humana.

La idea sería que estos modelos de pensamiento y expresión, considerados como valiosos y preservados por este motivo por la tradición, puedan funcionar como un estándar o patrón que quede en la mente de jueces y abogados, de forma que les pueda ser de ayuda para juzgar las composiciones de otros y elaborar las suyas propias (White 2012: 383).

Este uso de la literatura requiere - como es posible que haya podido apreciarse y se explicará a continuación - de una nueva forma de concebir y abordar las relaciones entre disciplinas.

\subsection{Una nueva aproximación a las relaciones interdisciplinares}

En efecto, puede decirse que la contribución de White y Weisberg en el campo del Derecho y la literatura, constituye un esfuerzo por romper con la visión predominante de segmentación y fragmentación de nuestras mentes y de la cultura, un fenómeno producido por la generalización, en todos los campos, del modo de proceder de los métodos científicos. Un ejemplo de ello podría apreciarse en la propia organización de las universidades. En ellas, cada rama del saber funciona interesándose solo por sus pautas de validez y su lenguaje, prescindiendo de toda conexión con la cultura como totalidad que confiere sentido. El trabajo interdisciplinar de estos autores buscaría romper esa división poco enriquecedora. Esta podría explicar el desconcierto que reflejaba la pregunta que, según White (1990: 18-20), con frecuencia le formulaban los académicos al comienzo de sus investigaciones en este campo: ¿qué tiene que ver el Derecho con la literatura? Con el tipo de relación que ambos autores establecen entre estas disciplinas, estarían demostrando que la vida no tiene por qué ser fragmentaria sino integradora. A través de su trabajo puede constatarse cómo, desde la literatura, surgen nuevas actitudes y preguntas que llevar al Derecho, de manera que este salga enriquecido. Y lo mismo podría decirse en sentido inverso.

Su trabajo no consiste, como se verá, en acudir a otra disciplina, la literatura, en busca de conclusiones sobre el mundo que puedan tomarse prestadas, sin más, o de argumentos que el Derecho pueda utilizar como una fuente de autoridad. No es correcto pretender encontrar en ella respuestas a preguntas explícitas sobre Derecho, ni ideas para ser invocadas en un argumento, ni métodos de análisis para ser transportados, tal cual, al Derecho. Las cuestiones jurídicas o legales deben responderse con los materiales del Derecho. 
Mirar al Derecho desde la literatura es, fundamentalmente, lo que White y Weisberg proponen. Al hacerlo, resultará inevitable que, de alguna manera, se produzca una transformación en la forma en que el primero es concebido, al quedar destacados en él los elementos que ambas disciplinas comparten. Estos resultan ser aspectos muy presentes en la actividad diaria del juez y del abogado $\mathrm{y}$, como nos descubren estos autores, sustanciales para el Derecho y su objetivo de hacer justicia. Sin embargo, apenas son tenidos en cuenta en la enseñanza del Derecho y no se les presta tampoco demasiada atención en la práctica del mismo. Poner la literatura al lado del Derecho supondría, como se decía, poner el foco sobre ellos, destacándose hasta qué punto la tarea diaria del jurista es una actividad del lenguaje, de la mente y el juicio, de dar un significado a los hechos y al Derecho mismo. Su actividad principal, como la del crítico literario, es la de leer los textos del pasado y escribir sus propias composiciones para hacerlos reales en las circunstancias únicas y actuales que se le presentan. La comprensión y el dominio de estas complejas actividades con el lenguaje, se convierten en las herramientas más poderosas para los jueces y abogados y en un instrumento esencial para que la justicia sea posible: entender lo complejo de traducir a cualquier lenguaje la experiencia humana; reconocer cómo la subjetividad gobierna toda observación de la realidad o de los hechos; tener capacidad para identificar y abordar, adecuadamente, las tensiones existentes en cada caso, al tener que traducir la historia del cliente al Derecho; saber gestionar las tensiones que se presentan entre el lenguaje ordinario y el jurídico, entre el pasado y el presente, entre lo que dice el Derecho y el sentido de lo correcto del jurista, etcétera.

La formación que requieren estas cuestiones, como se ha señalado anteriormente, no puede consistir en proporcionar un equipaje de datos, sino que el único método posible para su aprendizaje es el método de las humanidades. Al comparar las actividades de la mente y del lenguaje que se llevan a cabo en el Derecho con otras, en concreto, con las de la literatura, el abogado podría adquirir una mayor conciencia de lo que realmente hace y criterio para juzgarlo, en definitiva, la capacidad para hacerlo de una manera más efectiva, completa e inteligente, con un mayor sentido intelectual y ético (White 2008:15).

Esta relación interdisiciplinar no estaría basada, entonces, en la idea de que la literatura proporcione a los abogados y jueces una información que estos puedan utilizar. Lo que podrían obtener de ella, más bien, es una forma de pensar sobre las actividades de la mente y del lenguaje en las que se encuentran inmersos por su trabajo.

\subsection{Qué tipo de enseñanzas puede ofrecer a los juristas esta forma de relacionar el derecho y la literatura}

Los autores escogen textos literarios y abordan su lectura, según se ha mencionado anteriormente, como una conexión de la mente del lector con otra, 
la del escritor, la cual es, en muchos casos, una muy superior. A lo que debería conducir esta conexión es a una ampliación, complicación o cuestionamiento de las percepciones o ideas propias sobre nosotros mismos o sobre el mundo, en la medida en que la lectura de estos textos supone una apertura o exposición a otras mentes y a otras personas, a otros lenguajes, a otras formas de pensar, de ser, de imaginar el mundo y de hablar sobre él. Y esto es un proceso que será diferente en cada lector, ya que de la conexión de una mente con otra no cabe esperarse uniformidad sino variedad (White 1999: 55).

La literatura no es, para Weisberg y White, entonces, un artefacto meramente estético, destinado al consumo, sobre nada importante salvo el placer que produce y, por tanto, aparentemente contrario al Derecho. La literatura es, o puede ser, una poderosa forma de pensamiento y educación acerca de las cosas más importantes de la vida.

Como podrá comprobarse en el siguiente apartado, dedicado al método, las obras literarias objeto de análisis por estos autores pertenecen a géneros muy diversos. En el caso de White, el énfasis en su estudio no se pone en las diferencias entre ellas, sino, sobre todo, en la idea de que todas ellas participan del proceso de creación de nosotros mismos y del mundo a través del lenguaje. Una proporción importante del estudio de las obras literarias por parte del autor, se dedica, precisamente, a saber reconocer estos procesos en los diferentes textos, para aplicar lo aprendido, después, a los textos jurídicos. White muestra cómo cada actuación con el lenguaje sería reveladora de una cierta concepción de los lectores del texto, con los que el escritor, a su vez, habría establecido una relación de un cierto tipo. Asimismo, una determinada idea del mundo y de nuestra vida en común subyacería, siempre, a los diferentes usos del lenguaje. Para el reconocimiento y análisis de estas cuestiones, algunos ejemplos de las preguntas que el autor dirige a los textos literarios serían: ¿Quién es el lector ideal de este texto? ¿Es este un texto que aumente la capacidad de percepción y comprensión del lector o, por el contrario, lo que busca es manipularlo? ¿Establece el escritor con el lector una relación de igualdad, mostrándole honestamente todos los aspectos relevantes que deben considerarse antes de ofrecerle sus conclusiones, concediéndole, entonces, un espacio para que pueda enjuiciarlas? O, por el contrario, desde una posición de superioridad, no asumiendo y fomentando en el lector la capacidad de crítica y juicio, ¿le oculta en su discurso información, de forma que solo le ofrece aquella que conduce todo el argumento hacia un resultado, no siendo facilitados, entonces, con amplitud y honestidad, los elementos de juicio necesarios para que el lector pueda valorar, adecuadamente, esa conclusión? Según el modo en que se expresa el escritor, ¿manifiesta este un sentido amplio o estrecho de la naturaleza y las experiencias humanas? ¿A qué tipo de vida invita el texto? ¿Invita a una vida de búsqueda de significado y de aprendizaje o, por el contrario, se trata de un texto manipulador y autoritario, que solo deja opción a su asunción o reiteración por el lector? ¿Se trata de un texto 
que invite a la esperanza o a una vida de resentimiento, desesperación, odio y destrucción?

En la mayoría de los análisis que lleva a cabo White, los textos responden a estas preguntas desde parámetros que el autor considera valiosos. No obstante, su idea es que los juristas aprendan a dar su propia respuesta a estas cuestiones en su lectura de los textos literarios, adquiriendo y formándose, así, su propio sentido de lo adecuado, para después trasladar eso mismo a la lectura y escritura de los textos jurídicos. Teniendo en cuenta el punto de partida de que tanto el abogado y el juez, como el escritor, se verían inmersos en una tarea semejante de construir significados a través del lenguaje, el objetivo sería que, con el análisis e interiorización de esos ejemplos literarios, los juristas lleguen a tener un criterio, lleguen a formarse unos modelos de pensamiento y expresión que entren a formar parte de esos recuerdos desde los que uno construye significados en el mundo.

Sin embargo, en el caso de Weisberg, los textos literarios que este autor escoge, contienen, en su mayoría, patrones de expresión negativos. Como se verá más adelante, el objetivo que perseguiría el autor es que el jurista experimente la injusticia que el empleo de este tipo de lenguajes produce en personas inocentes, y ello a través de un conjunto de obras literarias que resultan ser especialmente ilustrativas del fenómeno. "When an individual perceives injustice, all that defined him as a person is likely to emerge» (Weisberg 1984: 13).

Es, para Weisberg, una cuestión capital el que comience a abordarse una educación de esta naturaleza en el Derecho, si se quiere evitar que se reproduzcan los grandes errores del pasado. La propuesta de Derecho y literatura de este autor nace, pues, no tanto de unos planteamientos teóricos respecto a lo que el Derecho debe ser, sino del estudio de unos hechos, de la identificación y el análisis de los errores cometidos por los juristas en el pasado, y de sus terribles consecuencias. Weisberg investigó, en concreto, la retórica jurídica empleada por los abogados franceses en el periodo de «Vichy», y las terribles consecuencias que esta tuvo sobre la comunidad judía. Para este autor, el papel que tuvo el lenguaje en el holocausto no ha sido una cuestión suficientemente estudiada. Del análisis de este período de la Francia ocupada y de la actuación de sus juristas -el cual ocupó gran parte de su vida académica y con el que consiguió gran reconocimiento, incluso, por parte de las instituciones francesas - el autor concluyó que el holocausto no hubiera alcanzado tales dimensiones si no hubiera sido por ciertas colaboraciones, como la de la los abogados franceses. Sin embargo, también pudo apreciar que la actuación de esta comunidad de juristas y sus consecuencias, la deportación de miles de judíos a los campos de concentración, no tuvieron su causa en un especial antisemitismo por parte de estos abogados, ni fue resultado de la violencia, presión o coacción nazi. Tampoco se debió a la circunstancia de que sus vidas corriesen peligro en caso de haber actuado de otra manera. Weisberg encontró la causa en la formación profesional que habían recibido estos abogados así como en el estado de la cultura de su tiempo. Estos elementos se 
unieron para hacerles incapaces de ver y combatir, eficazmente, la terrible realidad que tenían delante. No supieron defender con firmeza los principios constitucionales de igualdad y de libertad que estaban recogidos en la constitución francesa.

El autor llega a esta conclusión, tras el estudio de las leyes raciales que se promulgaron a partir de 1940 bajo el gobierno de Petain y, sobre todo, después de un minucioso análisis de la retórica jurídica que se originó en torno a aquellas. Según pudo comprobar, los abogados franceses, tanto públicos como privados, se entregaron, con enorme dedicación, a debatir algunos aspectos de las leyes en los que estas no eran claras, sin, salvo alguna excepción, atacar frontalmente la propia ley, sin que en ningún momento se cuestionase su legitimidad. Eligieron trabajar con las leyes raciales en lugar de desafiarlas, con el resultado de que la misma lógica que era utilizada por los abogados para salvar a uno de sus clientes, sin embargo, condenaba a otros. Utilizaron, pues, una lógica profesional rigurosa que sería admirable, según Weisber (1996: 4), si no fuera tan trágico el contexto. Pusieron en práctica las leyes de Vichy como si se tratara de una nueva legislación sobre puentes o carreteras. Las asumieron, trabajaron cómodamente con ellas, interpretándolas imparcial y fervientemente, elucubrando y discutiendo, sin considerar el odioso marco en que estas dudas legales nacían. Estos abogados utilizaron un tipo de retórica profesional, institucionalmente aceptada, que ayudó a hacer vivas esas leyes, favoreciendo su aplicación (Weisberg 1992: 146).

¿Por qué utilizaron los abogados franceses la retórica descrita? Weisberg (1992: 127-136) considera que esta pregunta es importante y no solo porque no ha sido adecuadamente respondida, sino porque de su contestación pueden extraerse importantes lecciones para los abogados de nuestro tiempo.

Como se ha adelantado en párrafos anteriores, para el autor, la Francia de Vichy simboliza, dramáticamente, la agonía de una cultura que, desde un siglo antes de los terribles sucesos, estaba mostrando la mentalidad del holocausto. Por esta razón, para entender verdaderamente lo que ocurrió en Vichy y para que algo así no vuelva a suceder, no puede prescindirse de un conjunto de obras literarias donde los escritores denuncian el estado de su cultura. El novelista moderno intuyó el desastre, e intentó transmitir a sus lectores que no todo estaba bien con los valores europeos. Ningún escritor pudo imaginar los horrores que vendrían, pero la desorientación descrita en sus novelas profetizó el angustioso final de una cultura que se estaba descomponiendo. Para los estudios literarios, el periodo del holocausto comienza en Europa un siglo antes de Hitler.

En este contexto, el autor pone el ejemplo de obras literarias como La nariz de Gogol o El proceso de Kafka. Weisberg muestra cómo, las lecturas o interpretaciones equivocadas de la realidad de los personajes de estas obras, amenazan con convertirse en las nuestras. Somos nosotros quienes, como les sucede a estos personajes, podemos malgastar nuestras vidas en detalles sin importancia, mientras que, como Kafka da a entender en muchas de sus historias, la verdadera realidad y los aspectos fundamentales de la vida están ahí. El autor 
considera que el fenómeno de evitar lo esencial era un rasgo muy característico y extendido de la cultura europea. Al igual que los personajes de estas obras, la linterna de la formación profesional de los abogados de Vichy les condujo a iluminar solo la esquina de un enorme fenómeno y a no tener en cuenta, o perderse, su significado fundamental. No actuaron, como se ha dicho, movidos por un especial antisemitismo. Weisberg profundizó acerca de qué tipo de personas eran estos abogados y encontró, en la mayoría de los casos, seres humanos cuyo comportamiento venía determinado, más bien por un carácter evasivo y poco comprometido, un rasgo que caracterizó a la cultura y las principales instituciones de Francia en ese período. (Weisberg 1984: 1-7).

A su vez, y como se verá más adelante, un conjunto de textos literarios entre 1862 y 1956, serían reflejo, en la interpretación que Weisberg (1984) hace de ellos, de otro rasgo característico de esa cultura: la escisión de la ética y el lenguaje. Los personajes de estas obras encarnan el legalismo formalista y la intelectualidad farragosa, pasiva y articulada a que dieron lugar los antiguos valores. Esta forma de pensar y hablar persuadió a muchos en su momento y aún hoy sigue haciéndolo, encontrando en ella una filosofía digna de emulación. Como se verá más adelante, Weisberg, en la lectura que lleva a cabo de ciertas obras literarias desenmascara, precisamente, esta filosofía, mostrando cómo, tras la retórica cínica, inteligente, formal y articulada de estos personajes, en su mayoría abogados, no hay más, en muchas ocasiones, que un profundo resentimiento.

El análisis de estas obras leídas de esta manera sería, pues, una actividad especialmente idónea para afrontar una de las tareas fundamentales de los juristas de nuestro tiempo. Esta consistiría, según el autor, en tratar de conjurar el riesgo que, para el Derecho, nos muestra el ejemplo francés de desconsideración y distorsión de las creencias básicas constitucionales. Es una lección que debe ser aprendida, porque esos principios constitucionales, por los que nos sentimos protegidos, existían también en Francia. Si no admitimos que algunas normas han emergido de esos hechos acontecidos en Europa y, que, por tanto, deben actuar de guía ética en la retórica y crítica del Derecho, estamos condenados a repetirlos (Weisberg 2002).

\section{MÉTODO}

Una vez expuestos un conjunto de planteamientos más abstractos y generales acerca del nacimiento, naturaleza y objetivos de esta relación interdisciplinar en la formación de los juristas, a continuación, se descenderá a un plano algo más concreto, de manera que lo descrito hasta ahora, de forma teórica, pueda hacerse más intuitiva, a través de ciertos ejemplos. Se hará referencia, para ello, a algunas de las obras literarias que utilizan estos autores, al tipo de análisis que realizan en su lectura, a los aspectos hacia los que dirigen la atención, así como a cuáles pueden ser las enseñanzas que extraer de ellas. 


\subsection{Calidad de pensamiento y expresión}

Un punto de partida y premisa fundamental que se encuentra en las propuestas tanto de Weisberg como de White, y que nacería de la visión del lenguaje - explicada anteriormente- que defienden estos autores en el Derecho, es la relevancia que los dos conceden, en los textos jurídicos, a un aspecto esencial de la literatura: la «literalidad» o la unión de forma y contenido en la determinación del significado de los textos. Esta característica de los textos literarios tendría como efecto, en los textos jurídicos, que el abogado, cuando escribe, no solo argumente sobre el resultado que trata de obtener, sino, también, sobre la versión del discurso legal que crea en su composición. En ella no solo estaría diciendo: «He aquí el caso cómo debería ser decidido» sino «este es el lenguaje en el que sobre este caso y otros similares ha de hablarse», «el lenguaje que estoy hablando es el lenguaje apropiado de justicia en nuestra cultura» (White 1990:34). Los abogados, al argumentar, están definiendo un modelo (bueno o malo) para el pensamiento legal, invitando a los abogados y los jueces del futuro a pensar y hablar como ellos hacen. Desde este punto de vista, cada decisión judicial no solo estaría diciendo: «Ese es el resultado correcto para este caso» sino, también, «esa es la manera correcta de pensar y hablar en este caso y otros parecidos» (White 1990: 102). El juez, entonces, en la decisión judicial, no solo está dando autoridad al resultado por el que argumenta, sino, también, a sus propios modelos de pensamiento y expresión, los cuales pueden ser, ellos mismos, al margen del resultado al que se haya llegado, autoritarios o democráticos, generosos o miserables, doctrinarios o abiertos a múltiples argumentos. Si una resolución judicial es expresada de una forma intolerante, deshonesta o autoritaria, estará - con independencia del resultado - trivializando la experiencia de las personas de las que habla y, con ellas, el Derecho mismo. Por el contrario, si en ella el juez se expresa de una manera abierta y generosa, concediendo importancia a los hechos y a las personas, dignificará su experiencia $\mathrm{y}$, al hacerlo, también el Derecho.

No son, por tanto, los resultados hacia donde estos autores dirigen su atención. En esta disciplina personas buenas y decentes, grandes profesionales, pueden estar razonablemente en desacuerdo sobre un resultado. Por ello, la excelencia tanto en la práctica del abogado como en la del juez, en los textos que producen, no es algo que tenga que ver, tanto, con un resultado correcto o incorrecto, sino, más bien, con la calidad en la forma o estilo, entendiendo por ello, el proceso de pensamiento e imaginación que conduce a unas conclusiones.

Para White, el buen estilo, como algo equivalente al buen razonamiento, a la larga, conducirá a los mejores resultados. Y no de forma automática, sino a través del modo en quedan afectadas las imaginaciones, las mentes y los sentimientos de aquellos que viven con el Derecho. Para el autor, la gran cuestión es si el Derecho se moverá en la dirección de trivializar la experiencia humana y a él mismo, o en la dirección de dignificar ambos (White 1999: 42). 
Siendo la calidad de la expresión un asunto tan relevante en el Derecho, no es infrecuente, sin embargo, que la escritura de los abogados consista, simplemente, en haber puesto juntas palabras: normas, citas, argumentos, conclusiones, todo ello de forma predecible, sin suscitar interés alguno, sin que se vea el trabajo de una mente individual.

Frente a la apariencia de que en Derecho se funciona por un proceso mecánico, alcanzando soluciones predeterminadas a través de un proceso de lógica a partir de la norma, estos autores, como se ha visto anteriormente, ponen el énfasis en demostrar la capacidad de aquel para albergar un pensamiento y una expresión que sea original, en donde no sea la máquina o el sistema, sino los abogados y los jueces, los principales actores. Es en ellos en quienes recae toda la responsabilidad.

Pero, como se ha visto, existe una especial tendencia en el Derecho a no asumirla. ¿Cómo podemos aprender a entender y resistir nuestra propia tendencia a escribir de forma mecánica o predecible? ¿Cómo aprender a estar presentes en nuestros escritos como mentes y personas diciendo lo que queremos decir?

Para comenzar a dar respuesta a estas preguntas White (2006: 51-60), por ejemplo, reflexiona sobre la manera en que se enseña a componer textos en la infancia. Se muestran a los abogados textos cuyos autores son niños. Aparentemente, están bien escritos, pero en ellos pueden descubrirse, sin embargo, la existencia de clichés, de expresiones impersonales y no elaboradas, de frases que su escritor ha oído una y otra vez pero que no ha hecho suyas. Llama la atención, también - como un elemento más que delata esa falta de presencia del escritor - la ausencia de organización en los elementos utilizados. En algunas de las descripciones estos aparecen simplemente enumerados, haciendo lo que se espera de ellos que hagan, sin que pueda apreciarse la experiencia personal en la observación de esos detalles.

De ello no puede deducirse que el escritor vea la vida en clichés, sino que, seguramente, es la forma de expresarse que ha aprendido en el colegio para obtener buenos resultados. Ha prescindido de su mente y experiencia, no ha dicho realmente lo que quiere decir, sino lo que pensaba que debía decirse, ha sido prisionero de las expectativas que le rodean. Al proceder así, está negando, de alguna manera, la realidad y el valor de su propia experiencia, de su propia mente. Está renunciando, en definitiva, a una de las características o capacidades más definitorias y de valor del ser humano. Negar o renunciar así a nuestra propia humanidad puede incapacitarnos a reconocer la de otros. Puede ser este un hábito de la mente de enorme trascendencia, no solo para el que lo tiene, sino para el mundo, ya que sobre él podría basarse la tiranía para adquirir su poder y su fuerza (White 2006: 55).

White (2006: 17-25) propone la lectura de La Divina comedia de Dante, como una obra literaria especialmente ilustrativa para combatir esta forma de escribir que prescinde de la propia experiencia individual. Se trata de un texto en el que, 
a través del personaje principal, el lector participa de los esfuerzos de una mente individual por encontrar significados mientras define y reconoce las dificultades y limitaciones de este proceso, haciendo partícipe al lector, como se ha dicho, de todo ello, ofreciéndole una experiencia que amplía su capacidad de percepción y juicio. Para el autor, una parte fundamental del significado de esta obra es que considera a su lector como el tipo de persona que puede aprender a preguntarse los interrogantes que Dante el viajero se hace. El escritor encuentra una manera de representar los juicios eternos hechos por el juez del universo que estimula la capacidad del lector de hacerse preguntas. Consigue que esté insatisfecho, una y otra vez, con la disposición eterna de muchas almas y con las explicaciones ofrecidas en su justificación, dejándole en una tensión entre el aparente compromiso con la justicia de Dios del poeta y los juicios y sentimientos contrarios que encuentra emergiendo en él a medida que lee el poema.

El lenguaje de clichés, a diferencia del que muestra la Divina Comedia, tendría que ver, entonces, con un tipo de lenguaje que tiende a suprimir, a no dar cabida o a estimular, la independencia de pensamiento y juicio en el lector.

Trasladando estas reflexiones al Derecho, este parece invitar, especialmente, a la utilización de fórmulas estandarizadas. Puede que también aquí exista el peligro de que los abogados estén satisfechos o prefieran formas de pensamiento y expresión rutinarias, muertas, estereotipadas y autoritarias, formas de imaginar el mundo mecanicistas y reducidas.

Pero, ¿qué tipo de resolución judicial sería aquella en la que, como se ha visto que ocurría en las redacciones infantiles, el juez no está presente en su prosa, al haber sido incapaz de decir, realmente, lo que quiere decir, no habiendo hecho el caso suyo, el objeto de su pensamiento y atención?

Y esas mismas preguntas podrían formularse respecto a los abogados. Parece que el trabajo que cabría esperar de ellos es el de unas personas capaces de escuchar lo que, como clientes, les contamos, y de responder a ello, para trasladar después esa conversación al Derecho y encontrar maneras de usar el lenguaje legal - transformándolo si es necesario- para decir, verdaderamente, lo que quieren decir sobre el caso (White 2006: 72-73).

De igual manera que Platón en Fedro trata los términos fundamentales del lenguaje filosófico como inciertos en su significado, un objetivo esencial sería que el abogado comprendiese que lo mismo puede ser verdad sobre los términos fundamentales de su discurso. Los términos de su lenguaje no deben ser utilizados como si hicieran de forma automática el trabajo que requiere el caso, sino como una materia que precisa atención crítica y ser transformada en sus manos. Como se ha visto anteriormente, el Derecho compartiría con la literatura - aunque no de la forma intencionada y artística que sucede en esta última - el hecho de que las palabras, en los textos jurídicos, no solo adquieren su significado de definiciones estáticas, sino también de su uso en combinación con otros términos (White 2005: 61-81). El abogado debe tomar conciencia de que él es, fundamentalmente, un escritor, un compositor de textos orales y escritos para 
quien una cuestión esencial es lograr la excelencia en el arte de hablar y de transformar, con poder y originalidad, el lenguaje en sus composiciones (White 2008:17).

Este aspecto creativo y transformador - que ambos autores destacan - de la tarea de los jueces y abogados debería coexistir, sin embargo, con la idea de que estos profesionales trabajan, siempre, a partir de un material heredado. Por este motivo, sería útil para ellos recibir algún tipo de formación acerca de cómo identificar ese material, cómo leerlo, interpretarlo y respetarlo de forma adecuada y responsable. Y ello, en un momento en el que las escuelas de Derecho prestan poca atención a estas cuestiones, algo que es debido, en gran parte, a la confluencia de ciertas tendencias dentro del Derecho norteamericano desde comienzos de los años setenta: como la influencia del movimiento law and Economics o la de las teorías postmodernas de crítica literaria. Ambas corrientes coincidirían en hacer prescindir al Derecho de su modo esencial y característico de funcionar a través de los textos del pasado que lo constituyen. Para los dos autores, este hábito supone una amenaza, no solo para el Derecho, sino también para la supervivencia de la propia democracia.

\subsection{Una gestión consciente de la herencia cultural}

Weisberg y White quieren destacar, por tanto, el hecho de que un rasgo fundamental de la actividad del abogado y del juez es que ambos trabajan, siempre, sobre un material heredado. Cuando alguno de estos profesionales se pregunta, por ejemplo, por el significado de una ley, tendrá que tener en cuenta todo el Derecho previo frente al que se asume ha sido escrita. El texto legal, en este sentido, siempre llama a su lector a integrar su significado con los otros textos que hacen el Derecho. Esta tarea exige, además, la labor previa, por parte de jueces y abogados, de identificar esos textos, momento en el que se enfrentarán a la compleja pregunta de qué juicios o decisiones con autoridad, hechos por otros, deben respetar y por qué. Jueces y abogados actúan, pues, sobre las bases que les proporciona su tradición, de tal manera que, gran parte del significado de lo que hacen, al igual que ocurre con los poetas, reside en lo que su trabajo supone frente a su contexto o tradición (White 2000: 120)

Una parte de la formación de los juristas debería dedicarse, entonces, a la comprensión del lenguaje del Derecho como un complejo sistema de significado hecho por otros, heredado y quizás transformado por ellos. Sería útil que comprendiesen que están inmersos en prácticas y procesos que les posibilitan hablar y, a la vez, los limitan, y que hacen mucho por conformar la manera en que imaginan y viven en el mundo (White 1994: 127).

En realidad, todas las personas, como usuarios del lenguaje y habitantes de una cultura, inevitablemente, estamos respetando el pasado, ya que este ha hecho lo que somos y nos ofrece los materiales de nuestro pensamiento. Las preguntas 
esenciales que deberíamos hacernos, entonces, dentro y fuera del Derecho son cuándo debemos respetar el pasado, por qué y cuánto debemos hacerlo.

Para abordar estas cuestiones White (1994: 276) hace de la «autoridad» un tema consciente sobre el que pensar y argumentar. La gestión del conflicto de las pretensiones que a lo largo de nuestra vida son hechas sobre nosotros - por nuestros padres, amigos, profesores, jueces, policías, legisladores, por toda la gente y las instituciones que conforman nuestros mundos privados y públicosasí como las de uno mismo sobre el mundo, constituye un proceso que, a veces, es realizado de una forma instintiva, pero, otras, lo llevamos al mundo consciente. Llama la atención la complejidad de este proceso si profundizamos en lo que realmente hacemos, al estar todos formados, en parte, por los lenguajes, instituciones y prácticas cuya autoridad cuestionamos. La línea entre lo imaginado y lo real, entre uno mismo y el mundo no está, entonces, tan claramente definida. Han sido y pueden ser estos momentos una oportunidad $u$ ocasión para el gran arte.

En efecto, White expone a los jueces y abogados a textos en los que el problema de gestionar la relación entre uno mismo y las autoridades en el mundo ha sido abordado de forma especialmente inteligente y poderosa. En este sentido, invita a analizar, por ejemplo, la obra literaria de una persona real, la poetisa Emily Dickinson, y al personaje de ficción, Fanny, la protagonista de Mansfield Park de Jane Austen. Ambas son mujeres que trataron de hacerse su propia voz frente a las fuerzas de su mundo, en el cual, las cualidades de sus mentes, sus necesidades y demandas, no eran tenidas en cuenta. La ejemplaridad que emerge del análisis de sus actuaciones con el lenguaje derivaría de que, en los dos casos, su rebelión no toma la forma de mera destrucción, sino de transformación (White 1994: 187-275).

Esta forma de gestionar la voz propia frente a la autoridad del mundo, de una manera civilizada y conciliadora, es un denominador común de las obras que White selecciona, y un modo de hacerlo que alcanzaría especial mérito y valor en dos discursos: El discurso de segunda investidura pronunciado por Abraham Lincoln en 1865 y el discurso desde el banquillo en el jucio de Rivonia ante el tribunal Supremo de Pretoria de Nelson Mandela en 1964. Los dos vivieron en un mundo injusto dominado por el odio y la guerra y, sin embargo, evocan en sus textos un estándar de vida civilizada que define otras y mejores posibilidades. Gran parte de lo que puede aprenderse de Mandela y Lincoln, cuando tratan de dar autoridad a sus puntos de vista frente a los del mundo, es que, cuando lo hacen, no producen un sentimiento destructivo o de desesperación, sino que lo convierten en un acto de esperanza.

En todos estos textos se produce un cambio respecto a la herencia cultural que siempre tiene lugar sobre lo familiar y heredado. En todos ellos la reforma es una parte tanto como la preservación.

Hasta ahora se han recogido algunas de las actividades - que estos autores estudian y desarrollan en sus propuestas de Derecho y literatura - propias del 
trabajo de jueces y abogados. El modo en que se analizan, como ha podido comprobarse, es a través de la observación de actividades semejantes realizadas por escritores y poetas, sacando así conclusiones que puedan resultar de validez para el Derecho. Pues bien, a continuación, se añadirá una más y quizá previa a todas ellas, que consiste en la preocupación que compartirían jueces, abogados y escritores por mejorar sus capacidades para observar y percibir la realidad.

\subsection{Una percepción adecuada de la realidad}

Otra actividad permanente en la vida de escritores, historiadores, abogados y jueces consistiría, entonces, en la observación de la realidad, de los hechos, una acción que, como se ha dicho, siempre estará gobernada por la subjetividad. Pues bien, la literatura puede ser, también, la mejor fuente de sentido, sensibilidad y empatía hacia las experiencias humanas. En este sentido, Weisberg (1988: 110) hace de ella un medio privilegiado para conocerse a sí mismo y para vaciarse de prejuicios, para llenarse de lo mejor que se ha dicho y hecho. En resumidas cuentas, para adquirir esa sabiduría o «intuición saludable» que permita llegar a ver la realidad sin distorsiones, accediendo al corazón de la misma a través de un sentimiento de empatía y de imaginación.

Para ello, Weisberg (1984) recurre, sobre todo, a obras de la literatura continental como: Apuntes del subsuelo, Los hermanos Karamazov y Crimen y castigo de Dostoievski, Salammbo y la Educacion sentimental de Flaubert, El extranjero y La caída de Camus. Estas novelas, cuyos protagonistas son juristas, no deben ser interpretadas como una sátira o crítica del Derecho mismo, sino que, en la lectura que el autor realiza de ellas, lo que se pone en cuestión es la actividad de sus intérpretes, los actores legales, como la mejor metáfora de la actividad comunicativa de los propios escritores. Estos veían cómo la complejidad formal en la literatura parecía convertirse en un fin en sí mismo, por encima de la exposición de valores morales, éticos y políticos. Los artistas literarios del siglo XIX se reconocieron a ellos mismos en ciertos aspectos del Derecho y el procedimiento legal. El uso del Derecho como tema novelístico tendría que ver, entonces, con una asociación de ambas profesiones y con el hecho de que los escritores encontraran en el Derecho la mejor manera de articular sus incertidumbres más profundas (Weisberg 1994: 157)

Weisberg desafía, pues, la interpretación que sobre estas obras han hecho aquellos que han visto en la retórica brillante de sus protagonistas una filosofía inteligente y digna de emular. Descubre a los héroes de ficción de estas novelas, abogados e intelectuales como unos personajes que, aun con gran talento verbal, carecen de un firme sentido de sus valores. Los personajes articulados de estas novelas se sirven de los procedimientos legales y las formulaciones filosóficas para satisfacer sus pulsiones más íntimas de venganza y resentimiento. Detrás de las formas frías u objetivas de los procedimientos legales, a menudo se enmascaran u ocultan los propósitos subjetivos más amargos. 
Las novelas de estos autores continentales enseñan, entonces, a ser escépticos con la palabra y, especialmente, con la palabra más eficazmente empleada por personas inteligentes y articuladas en posiciones de poder institucional. A algunas de estas novelas, junto con otras no continentales posteriores como Santuario de Faulkner, The Fixer de Malamud o Native Son de Wright, Weisberg las denomina Procedural Novels. La característica común a todas ellas es que puede identificarse una misma estructura tripartita consistente en una primera parte, la posición anterior, donde se relatan los hechos tal y como sucedieron, normalmente un crimen. La segunda parte suele ser una investigación preliminar que culmina en una nueva versión del suceso. A menudo, aunque no necesariamente, hay un juicio que produce la tercera versión de la narración del incidente producido. Lo que relatan con cuidado estos novelistas es el sutil distanciamiento que las sucesivas interpretaciones van experimentando con respecto al relato original de los hechos. Es precisamente esta estructura tripartita la que proporciona al lector la posibilidad de verificar los hechos anteriores al proceso en el que son juzgados, de manera que sea capaz de evaluar la interpretación que, de forma sucesiva, los actores legales hacen de ellos. Podrá así detectar las interpretaciones meramente subjetivas pero brillantemente articuladas que se hacen de aquellos, y sentir la injusticia de las consecuencias que estas producen sobre sus víctimas (Weisberg 1986: 981).

Es la cultura que reflejan estas obras, de un formalismo estético, pero meramente subjetivo y alejado o distorsionador de la realidad, lo que estos escritores denuncian en la literatura, a través de la reproducción de este mismo fenómeno en el Derecho. El interés formativo de estas novelas reside en que los novelistas confrontan a sus lectores con los riesgos que pueden derivarse de una comunicación brillante y eficaz pero manipuladora, éticamente cuestionable, la cual, en muchas ocasiones, es convertida en un fin en sí misma (Weisberg 1992: 38).

\subsection{Un sentido integrador y no excluyente de la justicia. La empatía}

Otra de las enseñanzas que podría proporcionar la lectura de ciertas obras de la literatura - que tendría relación con esa percepción adecuada realidad - sería la adquisición de un cierto tipo de empatía que condujera a su poseedor hacia una idea integradora y no excluyente de la justicia. Una obra, por ejemplo, que podría servir a este propósito es Ojos Azules de Toni Morrison. Esta novela se desarrolla en Ohio a principio de los años cuarenta y narra las crueldades a las que se ve sometida una niña negra, Pecola, cuyas míseras circunstancias junto a un padre violento la obligan, a menudo, a vivir con otras familias. El valor de esta novela reside en que pide a su lector que comprenda a esta niña, a pesar de las diferencias de tiempo, raza y sexo que puedan existir entre ellos, ya que este tipo de historias le inducen a ver al «otro»y, entonces, una vez que lo ha hecho, le obligan a esforzarse por ver el mundo desde su óptica. El lector, al leer esta 
novela, toma conciencia del riesgo que existe de que tanto él, como aquellos que tienen autoridad, eviten o no vean a los «otros», los diferentes. Hay un pasaje del texto en el que esto se haría más explícito, el que describe un momento en el que la niña entra a comprar unos caramelos en una tienda regentada por un hombre blanco de clase media. El lenguaje que utiliza el escritor para hablar de lo que sucede desafiaría al lector tanto a criticar al dueño de la tienda como a percibir que, ese mismo hombre, el dependiente, puede ser él. El abogado lector podría sentir, entonces, que corre el riesgo de tratar a los otros como aquel dependiente hizo con Pecola, de tener ese mismo tipo de miopía. Quizás le pueda pasar como a ese hombre, que no pudo ayudar a la niña, simplemente, porque no la vio (Weisberg 1992: 43).

Ciertas obras literarias permitirían, pues, acceder, como difícilmente de otro modo sería posible, a realidades distintas, lejanas o ajenas para el lector, aumentando así su capacidad de ver, percibir y comprender. Es responsabilidad del abogado y del juez mejorar sus habilidades de percepción en este sentido. El principio de igual dignidad de todos los seres humanos, por el hecho de serlo, como centro y fuente del Derecho, se lo exige. Constituye una herramienta imprescindible de sus trabajos, entonces, el poseer una formación sólida que les permita apreciar realidades diversas y, ello, con una conciencia amplia y no estrecha de la naturaleza y las experiencias humanas. La literatura permite un acceso a este tipo de conocimiento privilegiado. Un gran escritor es el que pone nombre a sentimientos y situaciones, elevándolos de esta forma al plano consciente. Muchas veces lo logra tras distanciarse de su realidad y su cultura, las cuales, en ocasiones, como le ocurrió al hombre de la tienda, oculta o no permite ver a los «otros». El escritor, entonces, se acerca a estos y los saca a la luz, mostrando sus padecimientos y su común humanidad, generando en los lectores un sentimiento de empatía hacia quien no existía hasta ese momento.

El énfasis se ha puesto, hasta ahora, en la necesidad de que los abogados y jueces aprendan a ser críticos o escépticos con la palabra brillantemente utilizada, en que sean capaces de desafiar y mejorar sus propias percepciones y motivaciones, en que pongan bajo examen sus valores y prejuicios, ya que, todo ello, inevitablemente, influirá en su trabajo. El éxito profesional del abogado, su retórica brillante y eficaz es apreciada por los escritores de la ficción moderna, como disociada de toda empatía y ética. Sin embargo, parece que, cuando esto último existe, como ocurre con los abogados de la literatura norteamericana del siglo $\mathrm{XX}$, es poco probable que ese éxito profesional se produzca. ${ }^{6}$ De nada les

\footnotetext{
${ }^{6}$ Frente al retrato sombrío de los abogados de la literatura continental y de algunas obras de Dickens como el de MR. Tulkinghorn o Mr. Vholes en La casa desolada, la cultura literaria norteamericana sí tiene palabras amables para los abogados, produciendo figuras comprensivas que, sin embargo, no consiguieron éxito profesional. Es el caso de Pudd'nhead Wilson de Mark Ttwain o de Max en Native Son, de Richard Wright, de Horace Benbow en Santuario de Faulkner,
} 
sirve ese informado sentido de justicia si no son capaces de comunicar eficazmente (Weisberg 1992: 51-92). A ambas cosas, pues, deberían aspirar jueces $\mathrm{y}$ abogados. Hasta ahora se ha puesto el énfasis en lo primero, fijémonos ahora en este segundo aspecto relativo a la eficacia.

\subsection{Una comunicación eficaz}

La literatura, como se ha visto, tendría mucho también que enseñar a este respecto. Podrían citarse a dos abogados de ficción con enormes dotes de persuasión: Portia en El mercader de Venecia de Shakespeare y el capitán Vere en Billy Budd de Melville. Ambos consiguen abrumar a su audiencia, logrando obtener con ello el resultado legal que deseaban. Lo consiguen porque los dos conocen lo que su audiencia «sabe oír» y encuentran las palabras adecuadas que apelan a sus valores e intereses. La clave de la lección sobre eficacia consistiría en que esta no ha de cifrarse solo, como es corriente que hagan los abogados, en el rigor, la exhaustividad o la lógica jurídica, sino también como nos enseñan los abogados de Shakespeare o Melville, en conocer o tener en mente a la audiencia interesada, sus necesidades y valores, en definitiva, en saber para quién se escribe (Weisberg 1987).

Son también los casebook que se estudian en las escuelas de Derecho un material donde encontrar modelos de escritura profesional de enorme eficacia. Entre ellos, Weisberg (1987: 11) destaca los escritos de juez Cardozo y, especialmente, una de sus más célebres decisiones judiciales: Hynes v. New York Central B. CO.221 N.Y. 229 Courts of Appeals of New York, 1921. Sin embargo, es grande la distancia entre la calidad literaria de los escritos de este juez y la escritura empleada por los abogados norteamericanos de los años setenta y ochenta. Weisberg llevó a cabo un minucioso estudio desde 1979 a 1984 sobre diferentes escritos de unos mil abogados en activo que le permitió conocer, de cerca, sus principales errores y deficiencias.

Fruto de este análisis es When Lawyers Write, un libro que reúne un conjunto de recomendaciones o reglas de estilo y organización, que no tendrían como objetivo una escritura más elegante o brillante, sino conseguir que sea más eficiente y eficaz, lo cual solo es posible, como se ha dicho, si el abogado logra trasladar a su escrito una conciencia adecuada de su audiencia. Conseguirlo significaría haber hecho desaparecer muchos de los defectos más usuales cometidos por los abogados en sus escritos. Weisberg destaca, de entre todos ellos, el poder fascinante que ejerce la lógica jurídica en su trabajo, lo cual les lleva, en ocasiones, a olvidar qué es lo fundamental para su audiencia. Otro error sería, como se ha mencionado anteriormente, la preferencia que detecta en ellos por la exhaustividad o el rigor, en detrimento de la eficacia. Ambos aspectos

de Ascher en El libro de Daniel de E.L Doctorow, de Sir Thomas en A Man for All Seasons o de Robert Bolt o Bibikov en The Fixer de Malamud. 
deberían coexistir y no entrar en competencia. El abogado debería ser consciente de que tan grave es omitir datos relevantes, como forzar al lector a crear un esquema que dé orden a los datos proporcionados y, por ello, casi el mismo cuidado debería dedicar a una exhaustiva compilación de información, como a poner orden en una expresión eficaz de la misma (Weisberg 1987: 39).

Hasta aquí, se han tratado de presentar algunos aspectos significativos de lo que puede suponer, para jueces y abogados, una formación literaria tal y como la conciben dos de los autores pioneros y principales en este campo. El objetivo, a través de estos ejemplos, no ha sido el de exponer con exhaustividad sus propuestas, ni el de entrar en debates académicos, sino el de mostrar e introducir en España algunas de las nuevas perspectivas y posibilidades, de los nuevos métodos que, para la enseñanza y práctica del Derecho, proporcionan los trabajos de estos autores.

\section{BIBLIOGRAFIA}

BOYD WHITE, J. (1982), «Law as Language: Reading Law and Reading Literature», Texas Law Review, 60, 415, 429-430.

BOYD WHITE, J. (1987), «Thinking about our Language», The Yale Law Journal, Vol. 96, No. 8 (Jul., 1987), pp. 1960-1983.

Boyd White, J. (1990), Heracle's Bow: Essays on the Rhetoric and Poetics of the Law, Chicago, The University of Chicago Press.

Boyd WHITE, J. (1990), Justice as Translation, Chicago, The University of Chicago Press.

BoYd White, J. (1994), Acts of Hope: creating Authority in Literature, Law and Politics, Chicago, The University of Chicago Press.

BOYD WHITE, J. (1999), From Expectation to Experience: Essays on Law and Legal Education, Michigan, The University of Michigan Press.

BOYD WHITE, J. (2005), Ordinary Language and Legal Lamguage, «Translation as a Way of Understanding the Language of Law», Milán, Giuffre Editore.

BOYD WHITE, J. (2006), Living Speech: Resisting the Empire of Force, New Jersey, Princeton University Press.

BOYD WHITE, J. (2008) «Establishing Relations Between Law and other forms of Thought and language», La Haya, Erasmus Law Review, 3, 3-22.

GEMMETTE, E. (1989), «Law and Literature: An Unnecesarily Suspect Class in the Liberal Arts Component of the Law School Curriculum», Valparaiso University Law Review, 23(3), 267-340.

GEMMETTE, E. (1995), «Law and Literature: Joining the Class Action», Valparaiso Law Review, 29(2), 665-859.

Nussbaum, M.C. (1995), Poethic Justice: Literary Imagination and Public Life, Boston, Beacon Press.

WEISBERG, R. (1984), The Failure of The World: The Protagonist as Lawyer in Modern Fiction, New Haven, Yale University Press.

WeISBERG, R. (1986), «Text into Theory: A Literary Approach to the Constitution», Georgia Law Review, 20, 946-979.

WeISBERG, R. (1987), When Lawyers Write, New York, Brown and Company. 
WeIsBerG, R. (1988), «Coming of Age of Some More: «Law and Literature» Beyond the Cradle», Nova Law Review, 23, 121.

WeisberG, R. (1992), Poethics and other Strategies of Law and Literature, New York, Columbia University Press.

WeIsBerG, R. (1994), «The Codification of Western Law and the Poethics of Diclosure», Cardozo Studies of Law and Literature, 6(2), 157-170.

WEISBERG, R. (1996), Vichy Law and the Holocaust in France, Reading, Harwood academic publishers.

WEISBERG, R. (2001), «Fish Takes the Bait: Holocaust denial and Post-Modern Theory», CSLL, 14(1), 131-141. 